\title{
AVALIAÇÃO DA ANÁLISE CRÍTICA COLETIVA DE PROJETO SOB A ÓTICA DOS ESTUDANTES DE ARQUITETURA E URBANISMO
}

\author{
Evaluation of collective critical analysis of design from the \\ perspective of architecture and urbanism students
}

\section{Paula Barros ${ }^{1}$}

RESUMO A prevalência de ambientes de ensino-aprendizagem de projeto caracterizados por uma rígida estrutura hierárquica tem sido recorrentemente apontada como um problema a ser enfrentado em prol da formação de profissionais críticos e compromissados com o bemestar social. Diante da necessidade de elevar os alunos a coprodutores do conhecimento ao longo do processo de ensino-aprendizagem de projeto, o artigo objetiva investigar como a Análise Crítica Coletiva de Projeto (ACCP), uma modalidade de assessoramento coletivo de projeto que vem sendo aplicada na oficina Problemas de requalificação de áreas e edificações urbanas, é avaliada pelos alunos do curso noturno de Arquitetura e Urbanismo da Universidade Federal de Minas Gerais (UFMG). A análise qualitativa dos dados obtidos através da aplicação de um questionário indica que, segundo a percepção dos discentes, a ACCP, dependendo das habilidades e competências do professor, pode facilitar a criação de um ambiente de ensinoaprendizagem mais horizontal e propício ao desenvolvimento da capacidade de (auto)crítica e autonomia dos alunos. Dentre os outros benefícios associados à técnica, cabe destacar: (i) ampliação do quadro de referência; (ii) promoção da aprendizagem coletiva; (iii) otimização da produção projetual; (iv) promoção da criatividade; e (v) desenvolvimento de habilidades requeridas pelo trabalho em equipe, como a de apresentar, comunicar, ouvir, perguntar e argumentar diante de um grupo.

PALAVRAS-CHAVE: Crítica, Autonomia, Ensino-aprendizagem de projeto.

ABSTRACT The prevalence of teaching-learning environments of design characterized by a rigid hierarchical structure has been recurrently cited as a problem to be faced for the sake of training critical professionals committed to social welfare. Bearing in mind the need to raise students to act as co-producers of knowledge, this article aims to investigate how Collective Critical Analysis of Design, a type of group crits that has been applied in workshops which deals with rehabilitation of urban areas and buildings, is evaluated by the students of architecture and urbanism at Federal University of Minas Gerais. The qualitative analysis of the data obtained through the application of a questionnaire indicates that, according to the perceptions of students, the Collective Critical Analysis of Design, depending on the abilities and skills of the teacher, can facilitate the generation of a critiquing setting more horizontal and favourable to the development of the ability to (self) critique and autonomy of the students. Among the other benefits associated with the technique, it is necessary to emphasize: (i) expansion of the reference framework, (ii) promotion of collective learning, (iii) optimization of design process, (iv) promotion of creativity, and (v) development of skills required by teamwork, such as communicating, listening, asking and arguing in front of a group.

KEYWORDS: Criticism, Autonomy, Teaching-learning design.

\section{How to cite this article:}

BARROS, P. Avaliação da análise crítica coletiva de projeto sob a ótica dos estudantes de arquitetura e urbanismo. Gestão e Tecnologia de Projetos, São Carlos, v. 11, n. 1, p. 83-94, jan./jun. 2016.

http://dx.doi.org/10.11606/gtp.v11i1.99202
Fonte de financiamento: Declara não haver. Conflito de interesse: Declara não haver. Submetido em: 20 jun. 2015 Aceito em: 17 dez. 2015 


\section{INTRODUÇÃO}

Na contemporaneidade, a promoção da autonomia de estudantes é uma temática importante e significativa dentro das questões pertinentes à área da docência do ensino superior. O último livro escrito por Paulo Freire, Pedagogia da autonomia: saberes necessários à prática educativa, publicado em 1996, enriquece sobremaneira o debate ao apresentar um modo de ensinar fundado no respeito à autonomia do aluno.

Paradoxalmente, evidências indicam a prevalência de ambientes de ensino-aprendizagem de projeto caracterizados por uma estrutura rigidamente hierárquica e pautada no autoritarismo e dogmatismo do docente (CARVALHO; SAVIGNON, 2012; MACIEL, 2013). Em ambientes verticais, como há muito diagnosticado, alunos são impelidos a desenvolver proposições projetuais alinhadas com as supostas expectativas do professor, em vez de assumirem uma atitude crítica que os impulsionaria a investigar por conta própria alternativas projetuais divergentes.

Partindo da premissa de que a diminuição da distância entre professor e alunos ao longo dos processos de ensino-aprendizagem pressupõe a adoção de uma atitude crítica por parte do professor em relação a sua própria atividade docente, é preocupante a constatação da existência de um reduzido número de estudos que se propõem a analisar como diferentes práticas didático-pedagógicas influenciam o desenvolvimento da capacidade de crítica e autonomia do aluno nos processos de ensino-aprendizagem de projeto no Brasil.

Por exemplo, uma pesquisa recente verificou a ausência de artigos que abordam técnicas didático-pedagógicas de projeto na SciELO, base de dados que armazena artigos publicados em periódicos de países da América Latina e a África do Sul (MONTEIRO; VIDOTTO, 2014). Utilizando-se como filtro de busca o termo "autonomia" no título dos trabalhos publicados em anais ${ }^{1}$ de importantes eventos nacionais na área de Ensino e Aprendizagem de Arquitetura e Urbanismo, apenas quatro em mais de 800 publicações são encontradas sobre o tema. Com o termo de busca "ensino" no título, são obtidos 60 trabalhos, dentre os quais apenas seis citam obras de autoria do educador Paulo Freire.

Dos dez trabalhos que compõem a amostra, apenas três relatam metodologias de ensino-aprendizagem de projeto. Em síntese, todas as metodologias analisadas objetivam o desenvolvimento da capacidade de crítica e autonomia do discente, a promoção de um processo de ensinoaprendizagem centrado no aluno e o desenvolvimento de um leque de habilidades e competências, como definem as Diretrizes Curriculares Nacionais (BRASIL, 2010) pela utilização de uma coletânea de técnicas. A leitura dos trabalhos indica que as novas tecnologias de informação não têm exercido (ainda) uma influência significativa no ensino-aprendizagem de projeto no Brasil.

Dentre as várias técnicas didático-pedagógicas reportadas, incluindo visitas técnicas, estudos correlatos, leituras orientadas e aulas expositivas, os assessoramentos são recorrentemente descritos como práticas de grande potencial de desenvolvimento da capacidade crítica do aluno, que traz consigo o desenvolvimento da autonomia. O termo assessoramento, cabe pontuar, tem sido utilizado para denominar técnicas relativamente distintas entre $\mathrm{si}^{2}$. Partindo do pressuposto de que processos de ensino-

Foram objeto de consulta os anais III Encontro Nacional de Pesquisa e Pós-graduação em Arquitetura e Urbanismo (2014), XXXIV Encontro Nacional sobre Ensino de Arquitetura e Urbanismo (2014) e III Simpósio Brasileiro de Qualidade do Projeto no Ambiente Construído (2013) e do 7 PROJETAR (2015).

Com relação ao número de discentes participantes, os assessoramentos são denominados individuais quando envolvem um aluno ou coletivos quando contam com a presença de mais de um aluno. Os assessoramentos podem envolver professor(es) e aluno(s) ou só alunos. A participação do(s) professor(es) e do(s) aluno(s) nos assessoramentos pode ser programada, aleatória ou sob demanda.

Independentemente do número de alunos envolvidos, os assessoramentos podem variar em termos do número de professores participantes. A participação do(s) professor(es) pode ser fixa, temporária ou eventual. Quando os assessoramentos contam com a presença de mais de um professor, eles podem atuar simultaneamente, conformando uma banca, ou alternadamente. 
aprendizagem de projeto e o processo de projeto estão necessariamente imbricados, a próxima sessão discute brevemente a importância da crítica, que traz consigo o desenvolvimento da autonomia, no processo de projeto.

\section{O PROCESSO DE PROJETO, A CRÍTICA E A AUTONOMIA}

A pesquisa em projeto é estabelecida como um campo de investigação na década de 1960 com a realização, em Londres, no ano de 1962, da Conferência em métodos sistemáticos e intuitivos na Engenharia, Desenho Industrial, Arquitetura e Comunicações (The Conference on systematic and intuitive methods in Engineering, Industrial Design, Architecture and Communications) (CROSS, 2007). Desde tal evento, também responsável pelo lançamento do "movimento dos métodos de projeto" (design methods movement), outras conferências são realizadas com o mesmo objetivo: ampliar a compreensão sobre o processo de projeto.

Com o passar do tempo, a pesquisa em projeto torna-se um tanto rígida e abstrata, sendo rejeitada por muitos durante a década de 1970 em função dos insucessos na aplicação dos métodos sistemáticos, ditos científicos, dentre outros fatores (OLIVEIRA; PINTO, 2009). Ao propor que as pesquisas desenvolvidas na década de 1960 correspondiam à primeira geração do movimento dos métodos, Horst Rittet (1973 apud CROSS, 2007) contribui para o revigoramento do campo, que se consolida na década de 1980 . O processo participativo de projeto nesse período emerge como o principal tema de interesse entre os pesquisadores ligados ao campo da arquitetura e urbanismo.

Os benefícios provenientes da inclusão de uma diversidade de pontos de vista, conhecimentos, experiências e ideias ao longo do processo de projeto, bem como a necessidade de compartilhamento das tomadas de decisão, dada a complexidade dos problemas espaciais, têm justificado, até os dias de hoje, a utilização de métodos participativos de projeto, como avaliações de pós-ocupação (KOWALTOWSKI et al., 2006). Desde a década de 1980, o campo da pesquisa em projeto tem se expandido continuamente, como ilustra o grande número de eventos, livros e periódicos que abordam temáticas ligadas à projetação.

O processo de projeto na década de 1960 era recorrentemente descrito como um processo linear (ou cíclico) composto por três atividades sequenciais: análise, síntese e avaliação (LAWSON, 1997). A análise corresponde à estruturação do problema, à síntese a geração de soluções e à avaliação do julgamento da solução. Apesar da razoabilidade de se pensar o processo de projeto enquanto uma série de atividades sucessivas, resultados de estudos empíricos têm refutado tal noção. Evidências têm indicado que o problema e a solução coevoluem em meio a atividades de análise, síntese e avaliação (DORST; CROSS, 2001; WILTSCHING; CHRISTENSEN; BALL, 2013).

Lawson (1997), um dos estudiosos do processo de projeto mais influentes na contemporaneidade, constata que: (i) o problema e a solução se retroalimentam ao longo do fazer projetual; (ii) toda solução pode ser indefinidamente incrementada assim como todo problema espacial pode ser indefinidamente reformulado; (iii) não há soluções projetuais corretas; (iv) há um número inesgotável de soluções para um dado problema, sendo algumas percebidas como mais aptas do que outras por certos indivíduos; (v) o processo de projeto necessariamente envolve julgamentos de natureza subjetiva; e (vi) todo processo de projeto é único e se define ao longo do fazer projetual.

Para Schön (1983), renomado pedagogo, o processo de projeto é um processo de "reflexão na ação", ou seja, reflete-se projetando e aprende-se

\footnotetext{
A crítica ao longo dos assessoramentos pode ser emitida exclusivamente pelo(s) professor(es), pelo(s) aluno(s) e professor(es), ou só pelo(s) aluno(s). A especificidade da crítica pode variar se direcionada a um trabalho ou a vários trabalhos. Há assessoramentos que incluem a produção de desenhos e outros pautados exclusivamente em verbalizações.
} 
a projetar projetando. Ao longo da projetação, a reflexão funciona como o motor propulsor das atividades de análise, síntese e avaliação (ANDRADE; RUSCHEL; MOREIRA, 2011). O processo de projeto enquanto um processo de reflexão na ação pressupõe a crítica, cuja importância tem sido destacada por vários autores, dentre eles Malard (2005, p. 90):

Partimos de um problema (ou situação-problema) que precisa de uma solução arquitetônica; elaboramos hipóteses de projeto (tentativas de solução); eliminamos aquelas que não resolvem problema (considerados todos os seus aspectos estéticos, tecnológicos e funcionais) e escolhemos aquela que nos parece ser a melhor. Para eliminação das soluções ruins (ou dos erros) nós usamos a crítica. Fazemos arquitetura por tentativa e eliminação de erros, tal qual um cientista faz ciência.

Ao destacar que os arquitetos, assim como os cientistas, têm seus trabalhos baseados em processos de tentativa (conjecturas) e erro (refutações), Malard (2005) faz referência às ideias de Karl Popper. Muitos pesquisadores vinculados ao campo da pesquisa em projeto têm sido influenciados pela obra desse filósofo, para quem a cientificidade de uma teoria (ou hipótese) reside na sua refutabilidade, ou seja, na possibilidade de ser mostrada falsa por meio da discussão crítica:

Quando falo em desenvolvimento do conhecimento científico, não estou a pensar numa acumulação de observações, mas sim no repetido derrubamento das teorias científicas e sua substituição por outras melhores ou mais satisfatórias [...] E isso na medida em que a análise crítica das nossas teorias nos leva a tentar testá-las. (POPPER, 2006, p. 293-292).

Sob a ótica de popperiana, por mais que os novos avanços tecnológicos (por exemplo, sistemas de desenho auxiliado por computador) tenham impactado o processo projetual (CARVALHO; SAVIGNON, 2012; KOWALTOWSKI et al., 2006), por mais que haja à disposição dos projetistas uma série de ferramentas e métodos de apoio às atividades de análise (por exemplo, entrevistas), síntese (por exemplo, tempestade cerebral) e avaliação (por exemplo, checklists) (KOWALTOWSKI; BIANCHI; PETRECHE, 2011; KOWALTOWSKI et al., 2006), a melhora da qualidade das soluções projetuais pressupõe o exercício da (auto)crítica.

Diante do exposto, reforça-se a necessidade de mais estudos que abordem práticas didático-pedagógicas utilizadas nas disciplinas de projeto com vistas a fornecer evidências empíricas que norteiem a atualização das metodologias de ensino-aprendizagem de projeto em prol do desenvolvimento da capacidade de (auto)crítica e autonomia dos estudantes de arquitetura e urbanismo.

Inserido nesse debate, o presente trabalho tem como propósito analisar como a Análise Crítica Coletiva de Projeto (ACCP) tem influenciado o processo de ensino-aprendizagem de projeto sob a ótica dos estudantes. A ACCP é uma modalidade de assessoramento coletivo que vem sendo empregada na disciplina Oficinas Integradas de Arquitetura, Urbanismo, Paisagismo e Tecnologia (OFIAUP): problemas de requalificação de áreas e edificações urbanas, ofertada pelo curso noturno de Arquitetura e Urbanismo da Universidade Federal de Minas Gerais (UFMG).

A ACCP foi selecionada como objeto de estudo por pretender o desenvolvimento da capacidade de (auto)crítica e autonomia dos alunos a partir da criação de um ambiente de ensino-aprendizagem mais horizontal e colaborativo. A próxima seção contextualiza a ACCP em relação à disciplina OFIAUP: problemas de requalificação de áreas e edificações urbanas e ao Projeto Político Pedagógico (PPP) do curso noturno de Arquitetura e Urbanismo da UFMG. 


\section{CONTEXTUALIZANDO A ACCP3}

O PPP do curso noturno de Arquitetura e Urbanismo da UFMG propõe um processo de ensino-aprendizagem pautado no enfrentamento de problemas, centrado no aluno e baseado na produção colaborativa do conhecimento por meio da crítica, como explicita a passagem a seguir extraída do referido documento:

O ensino/aprendizagem é mais efetivo quando o estudante é o sujeito da ação, desenvolvendo um processo de aquisição/produção de conhecimento. Esse processo se dá por tentativa e erro, com a eliminação do erro através da avaliação crítica. Nele, o professor não é aquele que detém e repassa o saber, mas faz parte de sua construção [...] Tal processo é centrado no enfrentamento de problemas, para quais se demandam soluções. (UNIVERSIDADE FEDERAL DE MINAS GERAIS, 2008, p. 4).

O PPP define as OFIAUP e Oficinas de Planejamento Urbano e Habitacional (OFIURB) como eixos estruturantes do curso, lócus da aplicação integrada dos saberes prescritos pelas Diretrizes Curriculares Nacionais (BRASIL, 2010), a serem abordados em nove Núcleos de Conteúdos. Cursado o ciclo de disciplinas obrigatórias dedicadas à fundamentação no primeiro período, cabe ao aluno definir o seu percurso acadêmico a cada semestre, como ilustra o Quadro 1.

Quadro 1. Estrutura curricular do curso noturno de Arquitetura e Urbanismo da UFMG.

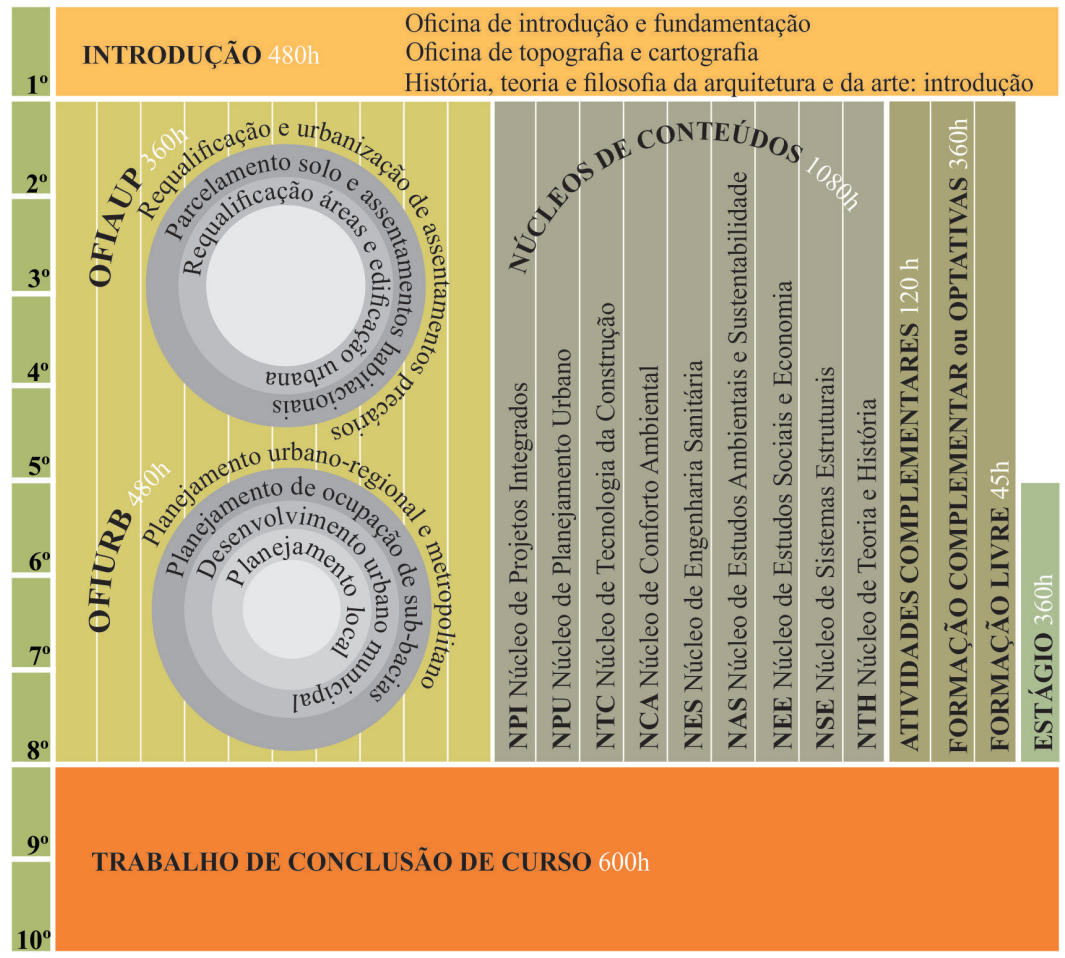

Fonte: Adaptado de Miranda (2015).

Uma estrutura curricular aberta, flexível, interdisciplinar e que incentiva diferentes formas de integrar a teoria e a prática, como propõe

A ACCP foi introduzida à autora pela professora Maria Lúcia Malard, que compôs a comissão indicada para desenvolvimento do PPP do curso noturno de Arquitetura e Urbanismo da UFMG e com quem ministrou, por alguns semestres, a OFIAUP: problemas de requalificação de áreas e edificações urbanas (turma B). 
o PPP do curso noturno, é vista como uma estratégia que contribui para o desenvolvimento da capacidade de (auto)crítica e autonomia do discente ao longo da sua formação (MASETTO, 2003).

As OFIAUP se desenvolvem sobre três temáticas (problemas de requalificação de áreas e edificações urbanas, problemas de parcelamento do solo e assentamentos habitacionais e problemas de requalificação e urbanização de assentamentos precários) e as OFIURB sobre quatro (problemas de planejamento local, problemas de planejamento de ocupação de sub-baciais, problemas de desenvolvimento urbano municipal e problemas de planejamento urbano-regional e metropolitano). Atividades complementares, disciplinas optativas e eletivas, estágio curricular supervisionado e o trabalho de curso ${ }^{4}$ foram também previstos.

Diante da necessidade de desenvolver uma série de habilidades e competências essenciais, um conjunto de técnicas didático-pedagógicas tem composto os planos de ação da OFIAUP. A metodologia de ensinoaprendizagem de projeto trabalhada tem sido continuamente atualizada a partir de uma consideração do PPP do curso, do tamanho da turma, da infraestrutura disponível, dos perfis dos alunos matriculados na disciplina e professor(es), da carga-horária (120 horas), do número de aulas por semana, e da ementa da referida disciplina, qual seja:

Abordagem crítica do espaço construído por meio do entendimento de seus aspectos sociais, psicológicos, econômicos, ambientais, técnicos e legais. Concepção do projeto de Arquitetura, Urbanismo e Paisagismo para requalificação de assentamentos urbanos (UNIVERSIDADE FEDERAL DE MINAS GERAIS, 2008, [s.p.]).

A ACCP, objeto de estudo da presente pesquisa, é uma modalidade de assessoramento coletivo que apresenta a seguinte sequência de procedimentos triviais: (i) projeção sobre o quadro branco (ou parede) das ideias projetuais desenvolvidas pelo(s) aluno(s), (ii) fundamentação oral das proposições pelo(s) seu(s) responsável(eis), (iii) crítica do trabalho em exposição pelos presentes, alunos e/ou professor(es), por meio de verbalizações e produção de desenhos no quadro, e (iv) síntese pelo(s) professor(es) das principais questões levantadas durante a sessão e estabelecimento de metas projetuais a serem alcançadas até a próxima sessão. Para possibilitar análises projetuais mais compreensivas e impelir o aluno a assumir uma responsabilidade maior pelo projeto em desenvolvimento, cada trabalho é analisado a cada sete dias, em datas previamente definidas, e apresentadas à turma no primeiro dia de aula.

Ao contribuir para o desenvolvimento da capacidade de (auto)crítica e autonomia dos discentes ao longo dos processos de ensino-aprendizagem, a ACCP estaria alinhada à ementa da OFIAUP, com o PPP do curso noturno de Arquitetura e Urbanismo da UFMG e com as tendências didático-pedagógicas contemporâneas.

\section{METODOLOGIA}

O objetivo do presente estudo, investigar como a ACCP é avaliada pelos alunos de arquitetura e urbanismo do curso noturno de Arquitetura e Urbanismo da UFMG, norteou a definição dos procedimentos metodológicos utilizados. O estudo envolveu a leitura de livros, artigos e trabalhos que tivessem relação com a temática em análise, a aplicação de questionário aos estudantes e análise qualitativa das respostas obtidas.

O questionário, técnica de pesquisa considerada eficiente para coletar dados de natureza perceptiva, foi estruturado exclusivamente com perguntas

Tanto a matrícula no estágio supervisionado quanto no trabalho de curso estão vinculadas à integralização de uma quantidade mínima de créditos em OFIAUP, OFIURB, núcleos de conteúdos e atividades complementares. 
abertas para oferecer aos participantes a oportunidade de se expressarem livremente acerca do tópico em pauta. Seis perguntas compuseram o instrumento ${ }^{5}$ : (1) Cite três pontos positivos da ACCP e três pontos negativos; (2) Cite três pontos positivos do assessoramento individual e três pontos negativos; (3) Na sua opinião, assistir à análise de trabalhos desenvolvidos por outros colegas é uma experiência positiva ou negativa? Por quê?; (4) Em quais circunstâncias você se sente confortável em comentar os trabalhos desenvolvidos por outros colegas durante as sessões de ACCP?; (5) Qual estratégia, na sua opinião, tende a favorecer a socialização de conhecimento em sala de aula: a ACCP ou o assessoramento individual? Por quê?; (6) Na sua visão, qual deve ser o papel desempenhado pelo(s) professor(es) ao longo dos assessoramentos de projeto?

Com o questionário, por e-mail, foi emitida uma nota explicativa da natureza e importância da pesquisa com o propósito de despertar o interesse dos alunos em participar voluntariamente da pesquisa como informantes. Onze questionários foram expedidos para estudantes que já haviam cursado a OFIAUP (turma B) e cujos e-mails faziam parte da lista de contatos da autora. Por questões éticas, apenas ex-alunos foram convidados a participar da pesquisa.

O material recebido, $25 \%$ dos questionários enviados (como anunciado pela literatura), foi armazenado de forma a garantir o anonimato dos participantes. Apesar de limitados por uma pequena porcentagem dos questionários retornados, os resultados obtidos fornecem informações relevantes sobre os significados associados às sessões de ACCP pelos estudantes de arquitetura e urbanismo no contexto do curso noturno de Arquitetura e Urbanismo da UFMG.

\section{RESULTADOS}

\section{Ampliação do quadro de referência}

As sessões de ACCP, segundo a percepção dos alunos participantes da pesquisa, favorecerem a expansão do quadro de referência, como sugerem os depoimentos a seguir: "[Assistir a sessões de ACCP é uma experiência] positiva, pois permite ao aluno uma auto avaliação do nível de seu trabalho, traz referências externas [...]" (ID001) ${ }^{6}$; "[A ACCP] estimula o compartilhamento de informações entre os alunos" (ID002); "A cada orientação obtemos novas informações, o que torna possível o trabalho de todos ser mais rico [...]” (ID003).

A importância atribuída à ampliação do quadro de referência ao longo dos assessoramentos fica também evidenciada nas seguintes opiniões: "[O assessoramento individual tem como desvantagem] não permitir visões de terceiros sobre o projeto" (ID001); "[Um ponto negativo do assessoramento individual é o] limite de sugestões e ideias apresentadas, limitando-se apenas às do orientador" (ID002); "[Nos assessoramentos individuais] às vezes alguma informação (algum detalhe, informações que enriquecem um trabalho) é dita a um grupo e a outro não” (ID003).

Esses resultados corroboram outro estudo empírico recente realizado no Brasil que verificou que assessoramentos em pequenos grupos tendem a ser percebidos pelos alunos como uma prática que facilita a troca de saberes (BRAGA; SANTOS, 2015). Partindo da premissa de que a projetação espacial é uma prática reflexiva, a utilização de técnicas de ensinoaprendizagem baseadas na socialização de saberes contribuiria para o incremento da qualidade das soluções projetuais e desenvolvimento da criatividade:

\footnotetext{
No questionário original, o termo “orientação coletiva” foi utilizado em substituição ao termo ACCP e o termo "orientação individual” foi utilizado em substituição ao termo assessoramento individual.

De forma a salvaguardar o anonimato, os participantes da pesquisa foram identificados aleatoriamente com ID001, ID002 e ID003.
} 
Quanto mais tivermos visto, experimentado e absorvido, mais pontos de referência teremos para nos ajudar a decidir que direção tomar: nosso quadro de referência expande. A capacidade para descobrir uma solução fundamentalmente diferente para um problema [...] depende da riqueza da nossa experiência. (HERTZBERGER, 1999, [s.p.]).

\section{Otimização da aprendizagem coletiva e da produção projetual}

A participação nas sessões de ACCP, seja como ouvinte atento ou crítico, otimizam a aprendizagem coletiva e a produção projetual, como sugerem os depoimentos a seguir: "A dinâmica da aula é mais rápida, eficiente e permite a participação do aluno em 100\% da aula”(ID001); “[As sessões possibilitam] o esclarecimento de dúvidas através do trabalho do outro grupo" (ID002); "Os alunos com projetos mais avançados cometem erros que os outros não irão cometer [...] não se perde tempo solucionando as mesmas dúvidas [...], a ideia da orientação coletiva [...] [é] aprender com todas orientações [...]. A qualidade do trabalho depende muito do aluno e de sua força de vontade, mas assistir a análise dos outros alunos (que muitas vezes serve para você mesmo) [...] faz que os trabalhos fiquem mais ou menos no mesmo nível” (ID003).

\section{Desenvolvimento da capacidade de (auto)crítica e autonomia}

A ACCP, segundo as passagens a seguir, favorece o desenvolvimento da capacidade de (auto)crítica e autonomia dos participantes, contribuindo para a elevação dos alunos a coprodutores do conhecimento: "[A ACCP] permite que os próprios alunos orientem uns aos outros, dando a sua opinião no trabalho de quem está sendo orientado no momento" (ID003); “A participação dos alunos pode trazer pontos não levantados pelo professor [...] [e] possibilita a percepção de erros ou perspectivas que o orientador não é capaz de fazer. [Assistir às sessões de ACCP] permite ao aluno uma auto avaliação do nível do seu trabalho [...]” (ID001).

A ocorrência da crítica entre alunos ao longo das sessões é, todavia, um grande desafio pelo fato de os modos de lecionar predominantes no contexto universitário brasileiro (ainda) serem centrados na figura do professor: " $\mathrm{O}$ problema é a carência de comentários por parte dos alunos [...] não me sinto à vontade de comentar o trabalho dos demais, uma vez que isso é muito mal visto por parte da maioria dos alunos. Sentem-se muitas vezes ofendidos e acham que cabe apenas ao professor, o único [...] capaz de esclarecer corretamente o trabalho" (ID002).

Aqui, o professor e o aluno ocupam posições opostas, cabendo ao primeiro transmitir, comunicar, orientar, instruir, mostrar, avaliar e ao segundo receber, assimilar e reproduzir por ocasião de avaliações. A substituição da ênfase no ensino pela ênfase na aprendizagem tem sido defendida em prol do desenvolvimento da capacidade de (auto)crítica, da autonomia e da valorização da formação continuada:

A ênfase na aprendizagem como paradigma para o Ensino Superior alterará o papel dos participantes do processo: ao aprendiz cabe o papel central, de sujeito que exerce as ações necessárias para que aconteça sua aprendizagem [...] O professor terá substituído seu papel exclusivo de transmissor de informações para o de mediador pedagógico ou de orientador do processo de aprendizagem de seu aluno. (MASETTO, 2003, p. 3).

Resultados de estudos prévios mostram que a prevalência de ambientes de ensino-aprendizagem de projeto caracterizados por uma grande 
distância entre professor(es) e discentes inibe a formação de profissionais críticos e compromissados com o bem-estar social por induzirem os alunos a adotar uma postura subserviente e passiva ao longo dos assessoramentos (CARVALHO; SAVIGNON, 2012). Ao favorecer o exercício da (auto)crítica, a ACCP estaria alinhada às novas tendências pedagógicas, ao PPP do curso noturno de Arquitetura e Urbanismo da UFMG e à ementa da OFIAUP.

\section{Desenvolvimento da criatividade}

Ao promoverem a atitude crítica, as sessões de ACCP facilitam a atividade de síntese, ou seja, a emergência de alternativas projetuais, como indicam os depoimentos a seguir: "[Um ponto positivo das sessões de ACCP é a aquisição de] novas ideias e inovações projetuais. Caberia aos instrutores cobrar argumentação [...] da classe afim de estimular novas soluções [...]”(ID002). Esses resultados corroboram outros estudos empíricos realizados no Brasil que verificaram que assessoramentos em pequenos grupos, ao favorecerem a atitude crítica, contribuem para o desenvolvimento da autonomia (BRAGA; SANTOS, 2015), facilitam análises multifacetadas (MONTEIRO; PINA; VIDOTTO, 2015) e estimulam o desenvolvimento da criatividade projetual (ELALI, 2013). As discussões, segundo Lawson (1997), ao estimularem análises sob diferentes ângulos, facilitam a emergência de alternativas projetuais. Algumas técnicas de apoio à criação, como Pontos de Vista de Outros (Other People's Viewpoints), baseiam-se em estimular análises e avaliações sob diferentes perspectivas com vistas a contribuir para o rompimento da inércia mental e facilitar a atividade de síntese (KOWALTOWSKI; BIANCHI; PETRECHE, 2011).

\section{O medo da crítica do grupo}

O principal aspecto negativo associado às sessões de ACCP pelos alunos é o desconforto psicológico provocado pela exposição de ideias, opiniões, experiências e conhecimentos, como ilustram as seguintes passagens: "[A sessão de análise crítica coletiva de projeto] pode inibir nos alunos mais tímidos o levantamento de questões relativas a seu trabalho" (ID001); "Vergonha de falar em público [e] desconforto com postura (comportamento) de outros alunos durante a sua apresentação [são sensações desagradáveis geradas pelas sessões de ACCP]” (ID002). Essas evidências, portanto, confirmam que o aluno recorrentemente não assume o papel de crítico ao longo das orientações por medo da crítica do grupo, exigindo, por via de consequência, esforços extras por parte do professor na criação de um ambiente de ensino-aprendizagem de projeto menos intimidante, mais horizontal e colaborativo (GIL, 2006).

\section{Desenvolvimento de habilidades requeridas pelo trabalho em equipe}

Apesar do desconforto psicológico associado à apresentação, comunicação e argumentação em público, o desenvolvimento dessas e outras habilidades demandadas pelo trabalho em equipe é valorizado pelos discentes: "[A sessão de ACCP] prepara o aluno a se expressar em público, defendendo suas ideias, ajuda na aquisição de soluções projetuais e novos modos de projetar através da orientação dos outros colegas [...]" (ID002); "[Uma desvantagem da assessoria individual é que a técnica] não estimula a prática de apresentações” (ID001); "Falta de prática do diálogo em grupo [é um aspecto negativo da orientação individual por resultar no] despreparo para a realidade profissional” (ID002). A importância do desenvolvimento de habilidades colaborativas na contemporaneidade tem sido enfatizada 
por pesquisadores da área de pesquisa em projeto: “Evidenciam-se também uma intensificação competitiva e a necessidade crescente de colaboração dos agentes de um projeto para produzir com eficiência e qualidade" (KOWALTOWSKI et al., 2006).

\section{Papel do professor de projeto}

A efetividade das sessões de ACCP na criação de um ambiente de ensinoaprendizagem mais horizontal e pautado na participação ativa do aluno, seja como crítico ou ouvinte atento, demanda que o professor assuma diferentes funções dependendo das circunstâncias: "Acho que o papel do professor é saber mediar [...]" (ID003); "Se o professor não tiver controle da turma, pode bagunçar a aula e seu rendimento diminuir" (ID001); "[O papel do professor é] orientar em relação aos termos técnicos de desenho e projeto. Deve também ser mediador dos debates em torno dos projetos apresentados e incentivar a participação dos alunos nas apresentações. Acima de tudo, ele jamais deve coibir ou reprimir ideias dos alunos" (ID001). Resultados de estudos prévios mostram que processos de ensino-aprendizagem de projeto excessivamente direcionados pelo professor induzem os alunos a adotar uma postura subserviente e acrítica ao longo dos assessoramentos (BRAGA; SANTOS, 2015), sendo que a adoção de uma postura paternalista ou demasiadamente crítica pelos professores de projeto tende a inibir o desenvolvimento da capacidade de crítica e autonomia do aluno (MARQUES; ELALI, 2011). A atuação docente em sala, portanto, é decisiva na criação de ambientes de ensino-aprendizagem mais horizontais.

\section{CONCLUSÕES}

Educar na contemporaneidade pressupõe formar para a (auto)crítica e autonomia. No âmbito do ensino-aprendizagem de projeto de arquitetura e urbanismo, sabe-se muito pouco sobre as práticas didático-pedagógicas em aplicação no Brasil. Em paralelo, evidências indicam que o ensinoaprendizagem de projeto no país tem se dado em ambientes verticais, nos quais predomina uma forte relação de dependência do aluno diante das críticas emitidas pelo professor ao longo das assessorias (CARVALHO; SAVIGNON, 2012; MACIEL, 2013).

Inserido neste debate, os resultados do presente estudo indicam que as sessões de ACCP, dependendo das habilidades e competências do(s) professor(es), podem contribuir para a estruturação de um ambiente de ensino-aprendizagem mais horizontal e facilitador da (auto)crítica, que traz consigo o desenvolvimento da autonomia. Dentre os outros benefícios associados à técnica pelos alunos, cabe destacar: (i) a ampliação do quadro de referência, (ii) a promoção da aprendizagem coletiva, (iii) a otimização da produção projetual, (iv) a promoção da criatividade, e (v) o desenvolvimento de habilidades requeridas pelo trabalho em equipe, como a de apresentar, comunicar, ouvir, perguntar e argumentar diante de um grupo.

Em outras palavras, as sessões de ACCP, baseando-se no compartilhamento e confronto de saberes, favorecem o aprendizado coletivo, a ampliação do cabedal de conhecimentos dos participantes, as análises e avaliações sob diferentes óticas, os posicionamentos críticos e o rompimento da inércia mental, contribuindo, eventualmente, para o desenvolvimento da criatividade projetual e otimização da projetação espacial. Ao promover hábitos colaborativos, a ACCP, segundo as evidências, favorece a capacitação do aluno a trabalhar em equipe.

A criação de um ambiente de ensino-aprendizagem de projeto menos hierárquico e que tenha o estudante como coprodutor do conhecimento, todavia, demanda um esforço extra por parte do professor, a quem cabe 
desenvolver uma série de habilidades e competências que lhe permita assumir papéis diferenciados, dependendo das circunstâncias, incluindo a função de mediador, motivador, orientador e moderador.

Partindo da premissa de que a dissolução das estruturas hierárquicas de ensino-aprendizagem de projeto com vistas a formar profissionais críticos não se dará a partir da replicação de práticas bem sucedidas em certos contextos, mas por meio da contínua atualização das práticas didáticopedagógicas por “docentes reflexivos”, parafraseando Schön (1983), esperase que as evidências empíricas do presente estudo estimulem a adoção de uma atitude crítica pelos professores de projeto em relação a sua prática docente.

\section{AGRADECIMENTOS}

Aos estudantes que participaram das sessões de análise crítica coletiva de projeto, aos estudantes que aceitaram participar desta pesquisa e aos professores com quem tenho tido a oportunidade de compartilhar reflexões sobre distintas práticas didático-pedagógicas, em especial a Professora Maria Lúcia Malard.

\section{REFERÊNCIAS}

ANDRADE, M. L. V. X.; RUSCHEL, R. C.; MOREIRA, D. C. O processo e os métodos. In: KOWALTOWSKI, D. C. C. K.; MOREIRA J. R. D.; PETRECHE, M. M. F. O processo de projeto em arquitetura: da teoria à tecnologia. São Paulo: Oficina de textos, 2011. p. 80-100.

BRAGA, G. P.; SANTOS, M. G. R. Dinâmica das assessorias de projeto: uma contribuição ao processo de autonomia do estudante de Arquitetura e Urbanismo. In: PROJETAR, 7., 2015, Natal. Anais... Natal: Universidade Federal do Rio Grande do Norte, 2015. 1 CDROM.

BRASIL. Ministério da Educação. Resolução no 2, de 19 de maio de 2010 Dispõe sobre as Diretrizes Nacionais para a oferta de educação para jovens e adultos em situação de privação de liberdade nos estabelecimentos penais. Brasília, DF: Ministério da Educação, 2010. Disponivel em: <http://portal mec.gov.br/index.php? option=com docman\&view $=$ download\&alias $=5142$ rceb002-10\&category_slug=maio-2010pdf\&ltemid=30192>. Acesso em: 4 fev. 2016

CARVALHO, R. S.; SAVIGNON, A. P. O professor de projeto de arquitetura na era digital: desafios e perspectivas. Gestão \& Tecnologia de Projetos, São Carlos, v. 6, n. 2 , p. 04-13, fev. 2012. Disponível em: <http://www. revistas.usp.br/gestaodeprojetos/article/ view/51007/55074>. Acesso em: 30 jan. 2014 DOI: http://dx.doi.org/10.4237/gtp.v6i2.215

CROSS, N. Forty years of design research. Design Studies, v. 28, n. 1, p. 1-4, jan. 2007 Disponível em:<http://www.sciencedirect.com/

science/article/pii/S0142694X06000792> Acesso em: 30 jan. 2015. DOl:10.1016/j. destud.2006.11.004

DORST, K.; CROSS, N.; Creativity in the design process: co-evolution of problem-solution. Design Studies, v. 22 n. 5, p. 525-437, set. 2001. Disponível em: <http://www-sciencedirect-com.ez27. periodicos.capes.gov.br/science/article/pii/ S0142694X01000096>. Acesso em: 5 dez. 2014. DOI: 10.1016/S0142-694X(01)00009-6.

ELALI, G. A. Criar ou não criar, eis a questão: breve discussão sobre o pape da criatividade no projeto de arquitetura. In: PROJETAR, 6., 2013, Salvador. Anais... Salvador: EduFBA, 2013. Disponivel em: $<$ http://projedata.grupoprojetar.ufrn.br/ dspace/handle/123456789/1328>. Acesso em: 30 jan. 2014.

FREIRE, P. Pedagogia da autonomia: saberes necessários à prática educativa. 25. ed. Rio de Janeiro: Paz e Terra, 2002.

GIL, A. C. Didática do ensino superior. São Paulo: Atlas, 2006

HERTZBERGER, H. Lições de arquitetura. 2. ed. São Paulo: Martins Fontes, 1999.

KOWALTOWSKI, D. C. C. K.; CELANI, M. G. C.; MOREIRA, D. de C.; PINA, S. A. M. G.; RUSCHEL, R. C.; SILVA, V. G. da; LABAKI, L. C.; PETRECHE, J. R. D. Reflexão sobre metodologias de projeto arquitetônico. Ambiente construído, Porto Alegre, v. 6, n. 2, p. 7-19, abr./ jun. 2006. Disponível em: <http://seer.ufrgs. $\mathrm{br} /$ index.php/ambienteconstruido/article/ view/3683/2049>. Acesso em: 13 fev. 2015. 
KOWALTOWSKI, D. C. C. K.; BIANCHI, G.; PETRECHE, R. D. A criatividade no processo de projeto. In: KOWALTOWSKI, D. C. C. K.; MOREIRA, J. R. D.; PETRECHE, M. M. F. O processo de projeto em arquitetura: da teoria à tecnologia. São Paulo: Oficina de textos, 2011. p. 21-56.

LAWSON, B. How designers think: the design process demystified. 3. ed. Oxford: Architectural Press, 1997.

MACIEL, A. B. Relações de ensino e aprendizagem no ateliê de projeto. In: CONGRESSO INTERNACIONAL DE ENSINO, 1., 2013, São Paulo. Anais... São Paulo: Faculdade de Arquitetura e Urbanismo; São Paulo: MACK, 2013. Disponivel em: <http:// projetocontemporaneo.wordpress.com>. Acesso em: 30 jan. 2014.

MALARD, M. L. Alguns problemas de projeto ou de ensino de arquitetura. In: MALARD, M. L. (Org.). Cinco textos sobre arquitetura. Belo Horizonte: UFMG, 2005. p. 79-114.

MARQUES, R. B.; ELALI, G. A. Em busca da autonomia: a percepção do trabalho final de graduação em arquitetura e urbanismo pelos formandos. In: PROJETAR, 5., 2011, Belo Horizonte. Anais... Belo Horizonte: UFMG, 2011. Disponível em: <http://projedata.grupoprojetar. ufrn.br/dspace/handle/123456789/948>. Acesso em: 29 jan. 2014.

MASETTO, M. T. Docência universitária: repensando a aula. In: TEODORO, A.; VASCONCELLOS, M. L. (Orgs.). Ensinar e aprender no ensino superior: por uma epistemologia pela curiosidade da formação universitária. São Paulo: Mackenzie/Cortez, 2003. p. 1-17.

MIRANDA, J. T. Estrutura curricular cursos de arquitetura e urbanismo da UFMG. [mensagem pessoal]. Mensagem recebida por: <paula-barros@ufmg.br> em 30 out. 2015.
MONTEIRO, A. M. R. G.; PINA, S. M. G.; VIDOTTO, T. C. A diversificação dos métodos de ensinagem: uma experiência no ensino de projeto de arquitetura. In: PROJETAR, 7., 2015, Natal. Anais... Natal: Universidade Federal do Rio Grande do Norte, 2015. 1 CDROM.

MONTEIRO, A. M. R. G. ; VIDOTTO, T. C. $O$ ensino de projeto de arquitetura nos periódicos da SciELO. In: ENCONTRO DA ASSOCIACÃO NACIONAL DE PESQUISA E PÓS-GRADUAÇÃO EM ARQUITETURA E URBANISMO, 3., 2014, São Paulo. Anais... São Paulo, 2014. Disponível em: < http:// www.anparq.org.br/dvd-enanparq-3/htm/ XFramesSumarioSC.htm>. Acesso em: 17 fev. 2015

OLIVEIRA, J.C.C.B.; PINTO, G. A. O movimento dos métodos de projeto. Arquitextos, São Paulo, ano 9, n. 105.06, fev. 2009. Disponível em: <http://www.vitruvius.com.br/revistas/ read/arquitextos/09.105/77>. Acesso em: 28 nov. 2014

POPPER, K. R. Conjecturas e refutações: o desenvolvimento do conhecimento científico. Coimbra: Almedina, 2006

SCHÖN, A. D. The reflective practitioner: how professionals think in action. Londres: Temple Smith, 1983.

UNIVERSIDADE FEDERAL DE MINAS GERAIS. Projeto pedagógico do curso de arquitetura e urbanismo noturno. Belo Horizonte: UFMG, 2008.

WILTSCHNIG, S.; CHRISTENSEN, B. T.; BALL, L. J. Collaborative problemsolution co-evolution in creative design. Design Studies, v. 34, n. 5, p. 515-542, set. 2013. Disponível em: <http://www. sciencedirect.com/science/article/pii/ s0142accp94X13000033>. Acesso em: 30 fev. 2015. DOI: 10.1016/j.destud.2013.01.002 